\title{
$O$ aparecimento do inseto como instante poético e reflexivo em "Uma esperança", de Clarice Lispector
}

\author{
Fabrício Lemos da Costa ${ }^{\mathrm{i}}$ \\ Sílvio Augusto de Oliveira Holanda ${ }^{\text {ii }}$
}

Resumo: O presente estudo tem o objetivo de analisar o aparecimento de um inseto como motivo poético e reflexivo em "Uma esperança", décimo quarto texto do livro Felicidade Clandestina (1998), de Clarice Lispector (1920-1977). Trata-se de um breve flagrante do pequeno vivente no cotidiano de uma família, transformado em matéria de ficcionalização. Assim, neste trabalho, desenvolveremos uma abordagem que considera o inseto como parte de um projeto literário desta escritora, que vê em miúdos animais uma oportunidade de capturar a "beleza" do instante em simplicidade e subjetividade. Para a nossa interpretação, recorremos aos estudos de Giorgi (2016), Maciel (2016), Nascimento (2012), Mendes (2000) e Santiago (2006).

Palavras-chave: "Uma esperança”. Clarice Lispector. Inseto. Cotidiano. Ficção.

\section{The appearance of the insect as a poetic and reflective instant in "Uma esperança", by Clarice Lispector}

\begin{abstract}
The present study aims to analyze the appearance of an insect as a poetic and reflective reason in "Uma Esperança", fourteenth text from the book Felicidade Clandestina (1998), by Clarice Lispector (19201977). It is a brief glimpse of the small livers in the daily life of a family, transformed into matters of fictionalization. Thus, in this study, we will develop an approach that considers the insect as part of a literary project by this writer, who sees in small livers an opportunity to capture the "beauty" of the moment in simplicity and subjectivity. For our interpretation, we used the studies of Giorgi (2016), Maciel (2016), Nascimento (2012), Mendes (2000) and Santiago (2006).
\end{abstract}

Keywords: "Uma Esperança". Clarice Lispector. Insect. Daily life. Fiction.

Submetido em: 28 ago. 2020

Aprovado em: 11 nov. 2020

$(\mathrm{cc}) \mathrm{EY}_{\mathrm{B} \text { - SA }}$

Esta obra está licenciada com uma Licença Creative Commons

Compartilha Igual 4.0 Internacional

ISSN 1679-6101

DLCV - Língua, Linguística \& Literatura

\footnotetext{
i Universidade do Estado do Amapá (UEAP). E-mail: fabricio.lemos1987@yahoo.com.br.

ii Universidade Federal do Pará (UFPA). E-mail: eellip@hotmail.com.
} 
E vi minha vida toda / contrair-se num inseto / Seu complicado instrumento / de voo e de hibernação.

(Drummond, "Rola mundo")

\section{INSETOS POUSAM NA FICÇÃO BRASILEIRA MODERNA}

Com o objetivo de melhor situar o lugar do pequeno inseto esperança no conto que carrega o seu nome mais popular, é interessante pensarmos o destaque para estes miúdos viventes num plano mais geral da ficção na literatura brasileira. Sobretudo, pensá-los como parte de um projeto literário de um tempo que coloca os mais variados animais como matéria ficcional de diversos escritores de uma geração, em que Clarice Lispector faz parte. Trata-se da década de 1960, na qual, segundo Gabriel Giorgi (2016) em seu estudo Formas comuns: animalidade, literatura, biopolítica, este tempo perfaz-se como momento privilegiado para toda uma animália. Nesse período, os bichos aparecem na literatura latino-americana tendo como base diversos motivos, como o intento político, por exemplo. Situando o seu objetivo, o pesquisador ressalta o lugar do animal na cultura, principalmente na segunda metade do século XX. Como viventes que são destaques na literatura, estes passam a inscrever diversas questões. Para ele:

Certos percursos da cultura das últimas décadas inscrevem o animal, e os espaços de relação, tensão ou continuidade entre o humano e o animal, para interrogar, e frequentemente contestar, a partir desse terreno, as biopolíticas que definem formas de vidas e horizontes do vivível em nossas sociedades: o animal é ali um artefato, um ponto ou zona de cruzamentos de linguagens, imagens e sentidos a partir de onde se mobilizam as molduras de significação. (GIORGI, 2016, p. 11-12).

Nesse bojo, pensando no viés que considera o realce do animal na produção literária, e, neste universo animalesco, refletindo sobre o variado leque de insetos que emergem como motivo ficcional, podemos citar um fragmento do texto "Circo do miudinho", escrito que faz parte do livro Ave, Palavra (1970), de Guimarães Rosa, autor da mesma geração de Clarice Lispector. Vejamos: "Isto é, êle se sai, muito vestido, de pé, de botas, é o grilo-de-botas, de mosqueteiros, fininhas plumas no chapéu, fininhos bigodes, e de espada à cinta, flanflim, só que inda traz, saindo-lhe dos cantos da bôca, um pedacinho verde de fôlha" (ROSA, 1970, p. 243, grafia do autor). No texto rosiano, todo o escrito é dedicado aos insetos, em flagrantes de miúdos animais, que, afetivamente, são inseridos em intenções poéticas em pleno cotidiano. 
Nesse sentido, como Clarice Lispector, Guimarães Rosa faz de um acontecimento comum, isto é, um inseto que aparece no campo do doméstico, um "espetáculo" ficcional. Assim, na esteira do pensamento de Giorgi (2016), citado anteriormente, os insetos inauguram, nessas literaturas, significações em imagens poéticas que corroboram uma capacidade pensante no que tange à escritura.

Vê-se, então, que os bichinhos adentram a literatura brasileira e, com eles, mobilizamse discussões diversas, as quais chamamos, aqui, de instantes poéticos, advindos de pequenos viventes. Neste caso, poder-se-ia falar de uma sensibilidade do artista que vê a realidade fora do eixo do "automático" e do comum, ao contrário, são novas maneiras de enxergar o mundo e a si mesmo, sendo estimuladas pelo contato com a fragilidade que é um inseto, como mostra a epígrafe deste trabalho, em que vidas podem ser "contraídas" em bichinhos quase imperceptíveis no dia a dia. Nesta abordagem, podemos também recorrer ao poema "Um besouro em toda parte", de Carlos Drummond de Andrade. Vejamos um trecho:

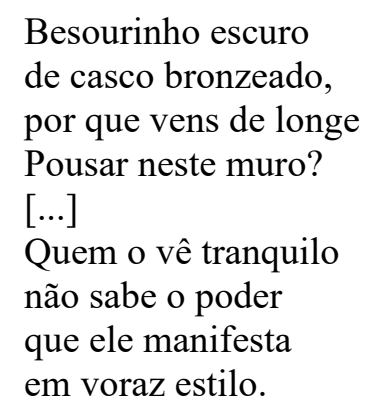

(DRUMMOND, 2002, p. 800-801).

No fragmento do poema, pode-se verificar, como no exemplo extraído do "Circo do miudinho", de Guimarães Rosa, o realce em torno do inseto. No texto de Drummond, dá-se por meio de um besouro. Em Rosa, no escrito citado, são borboletas, besouros, louva-a-deus, gafanhotos, grilos, cigarras que despontam de uma particularidade poética e reflexiva. Desta forma, é possível afirmar que os bichinhos "pousam" na literatura brasileira moderna como amálgama de um projeto que insere o animal como consciência artística. Fê-los, portanto, como matéria ficcional, sendo imprescindível que nos atentemos para a sensibilidade do artista, de algum modo, pois, de bichos tão pequenos, todo um universo reflexivo é configurado. Neste caso, consideramos relevante o termo "zooliteratura", utilizado por Maria Esther Maciel (2016) em Literatura e animalidade, em que a pesquisadora considera, no plano dos estudos dos animais na ficção, um termo mais geral, "aberto e menos cristalizado que o termo bestiário" (MACIEL, 2016, p. 14). 
Desse modo, considerando que o animal torna-se uso recorrente ${ }^{1}$ na literatura do século XX, faz-se mister pensarmos como estes viventes são abordados na zooliteratura brasileira, e, ainda, como são evidenciados no modo e estilo de cada autor, porque, os animais são vários e seus aparecimentos corroboram uma maneira particular de transformá-los em questão ficcional. Além disso, outro aspecto que precisa ser delineado, diz respeito aos destaques postos nos animais. Na literatura de Guimarães Rosa, por exemplo, é evidente a ênfase em relação aos bichos de maior porte, quase sempre boizinhos e cavalos, que fazem lembrar um universo sertanejo e jagunço. Entretanto, como mostramos por meio do "Circo do miudinho", por vezes, há um momento para o pequeno, aos minúsculos insetos.

No caso da ficção clariceana, podemos vislumbrar em seu romance amplamente conhecido, A paixão segundo G.H, um enorme destaque para o inseto. Na narrativa, uma barata submerge no doméstico, para levar a personagem mais longe, ou seja, à reflexão de si mesmo. Esta mulher, de inicias G.H., encontra uma barata no quarto que pertencia à empregada e, com o inseto, descortina e mobiliza, pela linguagem, significações que a levam para a mais latente, íntima e pulsante vivência:

De encontro ao rosto que eu pusera dentro da abertura, bem próximo de meus olhos, na meia escuridão, movera-se a barata grossa. Meu grito foi tão abafado que só pelo silêncio contrastante percebi que não havia gritado. [...] É que eu não esperara que, numa casa minuciosamente desinfetada contra o meu nojo por baratas, eu não esperava que o quarto tivesse escapado. Não, não era nada. Era uma barata que lentamente se movia em direção à fresta. (LISPECTOR, 1988, p. 32).

Assim, na ficção brasileira do século XX, temos um universo animalesco aparecendo em primeiro plano na literatura. No interior dessa diversa animalidade, os insetos têm um lugar representativo, como fica evidente em textos de Drummond, Rosa e Lispector. Para eles, quase sempre, espécies de reflexões emergem como instante poético no interior do cotidiano. Na rotina comum, minúsculos animais carregam os sujeitos para pensamentos mais amplos, fazendo-os ampliar questões em torno do íntimo de si mesmo, por exemplo. Passemos a esperança.

\footnotetext{
${ }^{1}$ Recorrente, aqui, significa que há o seu realce em primeiro plano, ou seja, como temática ou que estão intimamente ligadas a ela.
} 


\section{UMA ESPERANÇA ADENTRA O DOMÉSTICO}

"Uma esperança", décimo quatorze escrito do livro Felicidade Clandestina, tem como enredo o seguinte acontecimento. No inesperado do cotidiano, surge um inseto esperança no meio doméstico. Na fragilidade e delicadeza do pequeno bichinho verde, uma mãe e seu filho vislumbram aquela situação. Entre os quadros da parede, o animalzinho, descobre-se depois, parece "desejar" fugir de uma aranha escondida por detrás de um dos quadros. Neste fato, a mãe se surpreende com a sensibilidade do filho, que parece saber que uma esperança, bicho concreto e real, pode transformar-se em qualquer coisa de abstrato significado, alargando-se metaforicamente.

Nesse interim, o texto "joga" com esses dois planos trazidos pelo inseto. Trata-se, pois, da possibilidade da imagem pela concretude e pela abstração. Nesse ponto, é interessante apontar sobre a animália que emerge na literatura de tantos escritores brasileiros nesta época de produção, a segunda metade do século XX. Esses, quase sempre, são reais, portanto, são animais sendo animais, não possuindo marcas do humano, como fala e comportamentos morais e sociais, por exemplo, tampouco são fantasiosos ou hibridamente misturados. Vejamos seu início:

Aqui em casa pousou uma esperança. Não a clássica que tantas vezes verifica-se ser ilusória, embora mesmo assim nos sustente sempre. Mas a outra, bem concreta e verde: o inseto. Houve um grito abafado de um de meus filhos: - Uma esperança! ${ }^{2}$ e na parede bem em cima de sua cadeira! Emoção dele também que unia em uma só as duas esperanças, já tem idade para isso. Antes surpresa minha: esperança é coisa secreta e costuma pousar diretamente em mim, sem ninguém saber, e não acima de minha cabeça numa parede. Pequeno rebuliço: mas era indubitável, lá estava ela, e mais magra e verde não podia ser. (LISPECTOR, 1998, p. 92).

Neste momento, são necessários alguns apontamentos. Felicidade Clandestina é publicado pela primeira vez em 1971, pela editora Sabiá. Dessa maneira, podemos afirmar o interesse pelos animais no conjunto dessa coletânea de contos. Como pensa Gabriel Giorgi (2016, p. 8), desde a década de 1960, a animalização passa a fazer parte da ficção latinoamericana. Assim, no livro temos galinhas, macacos, baratas e esperança. Poder-se-ia, ainda, lembrarmos de outro livro de contos da escritora, como Laços de família, com primeira edição em 1960, pela Francisco Alves. Nele, vemos desfilar novamente galinhas e também búfalo, assim como demais animais presos em zoológicos, a exemplo da narrativa "O búfalo". No

\footnotetext{
${ }^{2} \mathrm{Na}$ expressão "Uma esperança!", dita pela criança, vemos prefigurada uma espécie de "encantamento" diante da descoberta que representa o inseto, como se tivéssemos, aqui, uma realidade vista pela primeira vez, perfazendo-se em intensidade e entusiasmo com a novidade.
} 
mundo "zoo" de Clarice, dialogando com a reflexão de Carlos Mendes de Sousa (2000) em Figuras da escritura, pode-se, inclusive, verificar "verdades" trazidas por insetos, dadas como fenômeno intuitivo, como se mostra no aparecimento da barata em A paixão segundo G.H. Para ele:

$\mathrm{Na}$ barata se procurou a antiquíssima verdade intuída. A barata é o mais antigo entre os mais antigos bichos que habitam a terra, tão antiga como necessária vida dos sinais (figuras) que são sempre uma escrita. Ao ler a obra de Lispector vamos deparando com uma singularíssima actualização dos imaginários animais numa obra que se distancia de uma pura reprodução das expressões arquetípicas enraizadas no inconsciente coletivo. (SOUSA, 2000, p. 235-236).

Pensando nestes possíveis "sinais", apontados pelo pesquisador português na ficção de Lispector, poder-se-ia ainda indagarmos no que tange ao caso da narrativa "Uma esperança", quais "verdades intuídas" podem ser caracterizadas naquele acontecimento aparentemente banal, ou seja, o simples surgimento de uma esperança entre os quadros da casa? Arriscamonos a dizer que se trata da possibilidade de uma exploração íntima de si mesmo, uma espécie de reflexão particular, que acaba singularizando o aparecer do inseto no meio doméstico.

Em síntese, como no romance A paixão segundo G.H., o inseto pode despertar o sujeito para zonas mais íntimas, como comprova o fragmento seguinte: "Andava mesmo devagar - estaria por acaso ferida? Ah não, senão de um modo ou de outro escorreria sangue, tem sido sempre assim comigo" (LISPECTOR, 1998, p. 93). Vê-se que o Eu da narrativa "emenda-se" ao bichinho, na tentativa de entender a sua real situação, o fato de estar, quem sabe, machucado. Para isto, recorre, na memória de si mesmo, em sua vivência, a possibilidade de entender o outro, o minúsculo inseto, como que participando ativamente daquele flagrante pelas vias da alteridade, da empatia e da subjetividade.

Ainda sobre esta capacidade de abstração mais complexa, porque se reveste de um intimismo arrolado como reflexão, portanto, pensamento, entendemos que a passagem que diz “Emoção dele também que unia em uma só as duas esperanças, já tem idade para isso”, citada anteriormente, carrega, justamente, este viés. Nesse bojo, compreendemos que o animalzinho "ativa" no Eu narrativo esse emaranhado de questões que ultrapassam o simples surgir de uma esperança num dia qualquer. Em "Uma esperança", dessa forma, um inseto se torna, no plano ficcional, pensamento, eis a clave da ficção clariceana. Entendemos o "pensamento", aqui, na maneira como elaborou Evando Nascimento (2012) em Clarice Lispector: uma literatura pensante. Segundo ele: 
Uma literatura pensante como a de Clarice é a que possibilita pensar o impensável; e só pode haver pensamento ali onde se dá o advento da alteridade enquanto tal, o outro como Outro ou Outra, em sua radical diferença. [...] Pensar o mundo é, pois, possibilitar o pensamento. (NASCIMENTO, 2012, p. 24).

Nesse ínterim, interessamo-nos pela afirmação de que a literatura pensante abarca o outro, como questão que emerge da alteridade. Em "Uma esperança", acreditamos estar implicado o pensamento, pois num acontecimento comum, um fato do mundo, ou seja, o surgimento de um minúsculo vivente, um Eu pensa o movimento da esperança, reflexão que nasce do próprio nome do bicho. Para isto, é a criança e sua capacidade de perceber mais longe, talvez pela ingenuidade, originalidade e atenção para as coisas não facilmente vistas pelo adulto inserido na velocidade e mecanicidade do dia a dia, que faz da situação um momento singular, por vezes, poético, como nos lembra o pensamento daquela mãe que se deixa envolver pelo espetáculo da esperança:

Uma vez, aliás, agora é que me lembro, uma esperança bem menor que esta, pousara no meu braço. Não senti nada, de tão leve que era, foi só visualmente que tomei consciência de sua presença. Encabulei com a delicadeza. Eu não mexia o braço e pensei: "e essa agora? que devo fazer?" Em verdade nada fiz. Fiquei extremamente quieta como se uma flor tivesse nascido em mim. (LISPECTOR, 1998, p. 94, grifo nosso).

No excerto, o poético se configura, dado como imagem de delicadeza que é um miúdo inseto verde, quase uma folha, pousando no braço da mulher. Destarte, são dessas situações repentinas, quando nada parecia acontecer, um inseto se mostra para "desautomatizar" o cotidiano, despertando no outro o pensamento e a capacidade para a sensibilidade das coisas simples. Neste sentido, ao adentrar o ambiente doméstico, o inseto quebra a rotina da casa, fazendo os habitantes que nela vivem prender-se naquele momento, expectando o delicado e o sensível caminhar do bicho, como se o tempo, diante daquele fato, fosse outro. Dá-se no caminho do sensível, como se tivéssemos, ali, aquele mesmo pedido de atenção para o surgir de uma flor no meio da correria, como faz lembrar o famoso poema "A flor e a náusea", de Carlos Drummond de Andrade: "Façam completo silêncio, paralisem os negócios/ garanto que uma flor nasceu" (DRUMMOND, 2002, p. 119).

Pensando nesta simplicidade que desorganiza a rotina diária da família, faz-se mister um breve excurso neste estudo. Antes de ser publicado na coletânea Felicidade Clandestina, 
em 1971, o texto "Uma esperança"3 apareceu pela primeira vez na coluna de crônicas do Jornal do Brasil, em que Clarice Lispector assinava aos sábados. Dessa maneira, no dia 10 de maio de 1969, como fizeram outros autores, a exemplo de Guimarães Rosa ao publicar "Circo do miudinho" no jornal $O$ Globo, em 25 de março de 1961, em que os insetos estão realçados, a autora faz "pousar" uma esperança, animal real e concreto na "vista" do leitor, fazendo este, quem sabe, desacelerar o ramerrão do dia com um pequeno inseto que pousa no espaço familiar.

Assim sendo, curiosamente, "Uma esperança" surge no espaço da crônica, veiculada no fim de semana, naquele veículo de comunicação, entretanto, ao ser inserido em Felicidade Clandestina, o texto passa a ser considerado conto, como se pode comprovar desde a primeira edição da obra, pela Editora Sabiá $(1971,1975)$, onde o termo "conto" aparece na capa do livro, ao lado do título.

Nesse bojo, pelo acontecimento dado na narrativa, acreditamos estar o texto mais próximo da crônica, mesmo considerando a dificuldade de classificar gêneros em Clarice Lispector, em que, talvez, fosse interessante vê-los apenas como "textos curtos", argumenta Silviano Santiago (2006, p. 159). Escrito breve, tem como enredo um flagrante de um inseto no meio do cotidiano de uma casa, em que tudo indica tratar-se da própria família da escritora. Ela e seus dois filhos. Em nosso entendimento, o escrito mostra-se interessante, pois nos encoraja a "olhar" a simplicidade, capturando-a, quem sabe, para transformá-la em uma "moldura" de afetividade e sensibilidade em relação ao outro, o menor dos animais, um miúdo inseto que se confunde com as folhas. Ele, que não tem quase nada de matéria corporal, transborda-se de "alma" na visão do menino.

- Ela quase não tem corpo, queixei-me.

- Ela só tem alma, explicou meu filho e, como filhos são uma surpresa para nós, descobri com surpresa que ele falava das duas esperanças.

Ela caminhava devagar sobre os fiapos das longas pernas, por entre os quadros da parede. Três vezes tentou renitente uma saída entre dois quadros, três vezes teve que retroceder caminho. Custava aprender.

- Ela é burrinha, comentou o menino.

- Sei disso, respondi um pouco trágica.

— Está agora procurando outro caminho, olhe, coitada, como ela hesita.

— Sei, é assim mesmo.

\footnotetext{
${ }^{3} \mathrm{https}: / /$ news.google.com/newspapers?nid=0qX8s2k1IRwC\&dat=19690510\&printsec=frontpage\&hl=pt-BR (Primeira versão de "Uma esperança" no Jornal do Brasil, Caderno b, p. 2). Acesso em: 20 de agosto de 2020.

${ }^{4}$ Cf. SANTIAGO, 2006, p. 159: “A partir dos anos 1920, com Mário de Andrade e Oswald de Andrade, e a partir dos anos 1940, com Clarice Lispector e Guimarães Rosa, as subdivisões tradicionais do gênero ficcional (romance, novela, conto, crônica) foram contestadas de maneira radical. [...] Essa é a razão pela qual será evitada neste trabalho a discussão sobre as rubricas tradicionais. Julgamos conveniente substituí-las pelo conceito de texto curto, que servirá para acolher indistintamente conto, crônica e anotação breve, diferenciando-os apenas do texto longo, ou seja, do que é qualificado tradicionalmente de romance ou novela."
} 
- Parece que esperança não tem olhos, mamãe, é guiada pelas antenas.

- Sei, continuei mais infeliz ainda.

Ali ficamos, não sei quanto tempo olhando. Vigiando-a como se vigiava na Grécia ou em Roma o começo de fogo do lar para que não apagasse. (LISPECTOR, 1998, p. 92-93).

Como fica evidente no excerto, ambos foram "capturados" por aquele inseto. Trata-se de um intento em apreciar o outro, o qual, na ficção, é transformado em instante reflexivo e poético. Pode-se dizer que o texto "Uma esperança" emerge de um fato banal, questão que o aproxima da crônica, entretanto, prefigura pensamentos mais amplos no sujeito, como se dá na indagação em torno da esperança como uma "alma", ou, ainda, sentimentos íntimos daquela mulher. Para isto, as duas, a concreta e a abstrata, invadem o doméstico. Assim, a segunda vem à tona, isto é, torna-se matéria de pensamento pelo bicho. Este, surge para estimular uma possível reflexão: "O menino, morta a aranha, fez um trocadilho, com o inseto e a nossa esperança. Meu outro filho, que estava vendo televisão, ouviu e riu de prazer. Não havia dúvida: a esperança pousara em casa, alma e corpo" (LISPECTOR, 1998, p. 94).

Seguindo a apreciação da esperança, eles ficaram na espreita, porque uma aranha escondida queria o pequeno animalzinho verde como alimento. Neste caso, perguntamo-nos, ficcionalmente, e, eles, o que queriam do inseto? No plano reflexivo, arriscamo-nos a dizer, desejam-na metaforicamente como "fogo do lar", portanto, como esperança que deixa de ser apenas corpo, matéria, coisa concreta, para tornar-se uma "alma", um sentimento e abstração que comporta qualquer coisa de pensamento mais íntimo. Queremos dizer, com isto, que o surgir de um pequeno animal verde perfaz-se como metáfora, estimulando a reflexão em torno de si mesmo.

Ficcionaliza-se, então, o animal, tornando-o imagem poética de uma vontade que nasce no Eu em meio de um espetáculo que é um inseto invadindo a casa e interrompendo os afazeres da família, pois, parar a rotina com o fim de vigiar um miúdo vivente corresponde, ao nosso ver, aos sentimentos mais nobres do sujeito. Trata-se, de um despertar para a vida em sua simplicidade, envolvendo-se com olhar ingênuo de criança, onde talvez esteja todo o propósito da literatura, isto é, tornar a visão da "realidade" menos mecânica para o que acontece ao redor, enfim, fitando-a como acontecimento sempre original, podendo-se extrair dela qualquer "beleza".

Em suma, se os animais passam a ser evidenciados na literatura do século XX, com destaque para a década de 1960, é no espaço jornalístico, nas chamadas colunas literárias, que eles encontraram um lugar privilegiado. Estes, na maioria das vezes, são assuntos de ficção 
em crônicas, ou, em espécies de anotações poéticas ${ }^{5}$, como podemos demonstrar também em vários textos de Guimarães Rosa, em que os bichos mais diversos “desfilam” em afetividade e sensibilidade quando vistos pela ótica artística. Mais tarde, a maioria destes escritos rosianos breves, publicados em jornal, foi inserida na coletânea Ave, Palavra (1970), organizada por Paulo Rónai.

Assim, consideramos o espaço do jornal importante para o realce da animalidade na literatura brasileira, pois, vários autores, entre eles, Clarice Lispector, publicavam semanalmente nestes veículos, geralmente, aos sábados. Neles, os bichos se mostram, quase sempre, arrolados no cotidiano, como é próprio da crônica, assim como, revelam-se, na maioria das vezes, reais e concretos.

Dessa maneira, no caso de Lispector, por exemplo, são baleias que se encontram encalhadas e violentamente vendidas, a sua carne, ainda vivas na praia, como se dá na crônica "A morte de uma baleia", publicada no Jornal do Brasil, em 17 de agosto de 1968, ou, ainda, um simples inseto que adentra o lar, como temos no corpus deste trabalho. Queremos dizer, com isto, que os animais estão por toda parte na literatura de Clarice Lispector, sendo “indispensáveis signos”, como aponta Carlos Mendes de Sousa (2000, p. 235) na ficção da autora. Esses são encontrados em contos, romances e na crônica. Essa última nos interessa, pois, podemos sublinhar que é por meio dela, veiculada num espaço mais democrático e aberto, isto é, o jornal, que alguns animais clariceanos são entrevistos, os quais têm a capacidade de "ativar" qualquer reflexão por parte do leitor.

Com isso, indagamo-nos: quereria a escritora que o leitor, aquele do periódico, passasse a olhar com mais atenção as coisas simples, quiçá com a visão de uma criança, um mínimo inseto que tenta se desviar de uma aranha? Não temos dúvida de que esteja neste sentido a beleza desse texto: um inseto "prende" a atenção de uma mãe e seu filho ao pousar na casa. Para apreciá-lo, é preciso parar os "negócios", vigiando-a em sua materialidade, vagareza, fragilidade, para, quem sabe, retirar-lhe qualquer "alma".

Retirar-lhe qualquer "alma", talvez, esteja configurado na possibilidade de transformar aquele evento como capacidade de rememorar uma intimidade ou uma vivência particular de si mesmo. Assim, pelo acontecimento externo, o pousar de um inseto, emerge a potência de remexer, no plano da lembrança, quem sabe, uma revolta. Aliás, na primeira versão de "Uma

\footnotetext{
5 No caso de textos rosianos em que os animais aparecem como "flagrantes poéticos", podemos citar os seguintes escritos: “Aquário (Berlim)", "Zoo (Whipsnade Park, Londres)", "Zoo (Rio, Quinta da Boa Vista)", "Zoo (Hagembecks Tierpark, Hamburgo — Stellingen)", "Zoo (Jardin des Plantes)", "Zoo (Parc Zoologique du Bois de Vincennes)", "Circo do miudinho", "Aquário (Nápoles)”.
} 
esperança", havia uma passagem intitulada "revolta" ao final do texto, retirada quando passou a fazer parte de Felicidade Clandestina. Ei-la:

Revolta

Quando tiraram os pontos de minha mão operada, por entre os dedos, gritei. Dei gritos de dor, e de cólera pois a dor parece uma ofensa à nossa integridade física. Mas não fui tôla. Aproveitei a dor e dei gritos pelo passado e pelo presente. Até pelo futuro gritei, meu Deus. (LISPECTOR, 1969, p. 2, grafia da autora).

Compreendemos, então, que, pelo animalzinho, há um despertar para questões mais íntimas naquela mulher. Entende-se, com isto, que o aparecimento de um inseto, longe de ser um acontecimento que poderia tornar-se esquecido e não percebido com cuidado, ao contrário, ficcionalmente, eleva aquela mãe para zonas subjetivas, singularizando-se o fato, haja vista que estamos no campo do literário. Neste sentido, uma esperança, o concreto e verde, mencionado no início do breve texto, rompe também com as fronteiras do material, para fazer vir à tona o subjetivo, a "alma".

Ao final do texto, a mulher, ao lembrar de outra vez que uma esperança pousara em seu braço, diante da leveza do bichinho, diz não ter acontecido nada, todavia, acreditamos ter acontecido tudo naquele evento, na verdade, é mister, por vezes, ver sempre as coisas pela ótica da simplicidade, assim como, revela-se como se vistas pela primeira vez. Então, ao flagrar e capturar em imagem poética a singeleza de um pequeno animal, resgata-se o valor que é enxergar o mundo em sua beleza, como se passa na vagareza de uma esperança. Assim, brincando com seu nome popular, na esperança de salvar o inseto verde, parte da família interrompe a rotina, para fazer o animalzinho escapar do destino funesto. Nessa situação, a mulher "chama" o menino para pensar também todo o natural que é o "mundo comível", representado pela aranha:

Foi então que farejando o mundo que é comível, saiu de trás de um quadro uma aranha. Não uma aranha, mas me perecia "a" aranha. Andando pela sua teia invisível, parecia transladar-se maciamente no ar. Ela queria a esperança. Mas nós também queríamos e, oh! Deus, queríamos menos que comê-la. Meu filho foi buscar a vassoura. Eu disse fracamente, confusa, sem saber se chegara infelizmente a hora certa de perder a esperança:

- É que não se mata aranha, me disseram que trás sorte...

- Mas ela vai esmigalhar a esperança! respondeu o menino com ferocidade. (LISPECTOR, 1998, p. 93).

Infere-se, desta passagem, o interesse da mulher em destacar um mundo orgânico, "comível", que "fareja" qualquer coisa de ferocidade e selvagem modo, em que "esperança", 
aquela "concreta e verde" (LISPECTOR, 1998, p. 92), naturalmente, é comida. Deste modo, trata-se, aqui, de uma consciência para o "espetáculo" da natureza prefigurada em cadeia alimentar, onde um bicho come o outro para a sobrevivência, preservando-se o harmônico ciclo natural. Neste ínterim, se o menino já tem idade para pensar a esperança como abstração, no fundo, como vigor de uma "alma", precisa ter consciência também para saber da esperança real, o bicho concreto, "não a clássica que tantas vezes verifica-se ser ilusória" (LISPECTOR, 1998, p. 92), mas, uma realidade comível.

Em suma, no escrito, tem-se a tomada de consciência para as duas esperanças: a abstrata e a real comível. Poderíamos sublinhar, neste evento, considerando o mundo infantil, que, no nível metafórico, a possibilidade da esperança real ser "esmigalhada", realça os pequenos "choques inesperados" da vida, como se esta mostrasse, em acontecimentos banais e simples, o decorrer do que seja existir, em que, quando tudo parece correr bem, há sempre uma aranha por detrás de um quadro na espreita. Esta última, ao contrário de representar a "inimiga", faz parte deste "jogo" natural, pois existir não significa estar sempre confortável e seguro no mundo, antes, tenta-se aproveitar o sofrimento, como demonstra aquele trecho de "revolta", como dissemos, suplantado na coletânea, em 1971. Diz-se, "aproveitei a dor e dei gritos".

Do aproveitamento do doloroso, que é a própria vida, como a mulher afirma no trecho em que se aproxima ${ }^{6}$ do inseto, especificamente sobre o momento de perigo e possível machucado do bichinho, revela-se, ao mesmo tempo, dialogando com Silviano Santiago (2006), a possibilidade de pensarmos uma espécie de "imunidade" e força animal com que ela se identifica ${ }^{7}$. No início do ensaio, quando o crítico ressalta uma carta em que Clarice Lispector envia ao escritor Lúcio Cardoso, em decorrência de uma viagem da escritora, comenta-se que "a animalidade imuniza a pessoa contra os sentimentos melosos e piegas, como o choro e saudade, enrijecendo-a e levando-a ao repouso na imobilidade da viagem" (SANTIAGO, 2006, p. 157-158). Dessa maneira, ao aparecer de um pequeno inseto, inferimos que todo um mundo íntimo pode ser vivido ou rememorado como viés subjetivo, num acontecimento de "alma". Dá-se, todavia, no instante de um dia comum.

\footnotetext{
${ }^{6}$ Cf. LISPECTOR, 1998, p. 93: “Ah não, senão de um modo ou de outro escorreria sangue, tem sido sempre assim comigo."

${ }^{7}$ Identificar-se com o animal, aqui, significa, na verdade, enfatizar o interesse pelas experiências que pertencem a ambos, uma espécie de "comunicação" ou lugar comum dos viventes, humanos ou não humanos, como no texto "Uma esperança", em que é possível ouvir ecos em relação ao perigo e à iminência da morte de um inseto, comido por outro. Cf. SANTIAGO, 2006, p. 160: "Vida e morte não são temas literários restritos unicamente à natureza humana. Deixam-se recobrir pela variadíssima gama de experiências comuns a todos os seres vivos."
} 


\section{CONSIDERAÇÕES FINAIS}

Na ficção de Clarice Lispector, como aponta a sua fortuna crítica, é recorrente a figura dos animais, vistos nos contos, romances e crônicas. No que diz respeito ao gênero literário, desenvolvemos, neste estudo, uma questão particular sobre o corpus de nosso trabalho. $\mathrm{O}$ escrito "Uma esperança" foi publicado pela primeira vez no Jornal do Brasil, no sábado do dia 10 de maio de 1969, no caderno dedicado à cultura. Neste veículo de comunicação, Lispector assinava, sempre no fim de semana, crônicas na coluna dedicada à este gênero. Todavia, em 1971, o texto apareceu no livro Felicidade Clandestina, uma coletânea de contos, publicado pela Sabiá, sendo reeditada, mais tarde, pela mesma editora, em 1975. Assim, pela aproximação com a crônica, abordamos o surgir de um inseto, a esperança, pela via do flagrante do minúsculo vivente no cotidiano de uma casa, o qual tudo leva a crer tratarse da própria família da autora.

Nesse flagrante, dado na rotina, vê-se um acontecimento simples interrompendo o dia comum de parte de integrantes desta família, fazendo-os pensar o perigo do inseto diante de uma aranha que se espreita para comer o primeiro. Além disso, corrobora-se, por meio do nome do bichinho, a possibilidade de alargar-se, metaforicamente, o pensamento em relação ao que seja a esperança em sentido abstrato, introduzido, inclusive, pela criança.

Em síntese, consideramos o texto "Uma esperança" como exemplar de um envolvimento com os animais, os mais diversos, na ficção da década de 1960, principalmente latino-americana. Em vários escritores da literatura brasileira, como Guimarães Rosa, Carlos Drummond de Andrade e Clarice Lispector, a animalidade emerge como plano principal, pois são destacados em temáticas, arrolando-se como "signos" políticos, afetivos, poéticos, ou, como se verifica no texto analisado, aqui, como reflexão que nasce no dia a dia, em que a visão da criança demonstra, na verdade, o pensamento em toda a sua singeleza e simplicidade.

\section{REFERÊNCIAS}

ANDRADE, Carlos Drummond de. Rola mundo. In: ANDRADE, Carlos Drummond de. Poesia completa. Rio de Janeiro: Nova Aguilar, 2002, p. 139-141.

ANDRADE, Carlos Drummond de. Um besouro em toda parte. In: ANDRADE, Carlos Drummond de. Poesia completa. Rio de Janeiro: Nova Aguilar, 2002, p. 800-803.

ANDRADE, Carlos Drummond de. A flor e a náusea. In: ANDRADE, Carlos Drummond de. Poesia completa. Rio de Janeiro: Nova Aguilar, 2002, p. 118-119. 
GIORGI, Gabriel. Formas comuns: animalidade, literatura, biopolítica. Tradução: Carlos Nougué. Rio de Janeiro: Rocco, 2016. 238 p.

LISPECTOR, Clarice. Uma esperança. In: LISPECTOR, Clarice. Felicidade clandestina. Rio de Janeiro: Rocco, 1998, p. 92-94.

LISPECTOR, Clarice. Uma esperança. Jornal do Brasil (Caderno b), Rio de Janeiro, n. 28, p. 2, 10 mai., 1969.

LISPECTOR, Clarice. A paixão segundo G.H. Brasília: CNPq, 1988. 366 p. (ed. crítica organizada por Benedito Nunes).

MACIEL, Maria Esther. Literatura e animalidade. Rio de Janeiro: Civilização Brasileira, 2016. 174 p.

NASCIMENTO, Evando. Clarice Lispector: uma literatura pensante. Rio de Janeiro:

Civilização Brasileira, 2012. 303 p.

ROSA, João Guimarães. Circo do miudinho. In: ROSA, João Guimarães. Ave, Palavra. Rio de Janeiro: J. Olympio, 1970. p. 241-244.

SANTIAGO, Silviano. Bestiário. In: SANTIAGO, Silviano. Ora (direis) puxar conversa. Belo Horizonte: Ed. UFMG, 2006. p. 157-191.

SOUSA, Carlos Mendes de. Clarice Lispector. Figuras da Escrita. Braga: Universidade do Minho/Centro de Estudos Humanísticos, 2000. 506 p. 